\title{
Idiopathic splenomegaly in childhood and the spectrum of RAS-associated lymphoproliferative disease: a case report
}

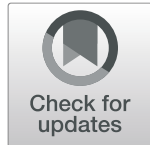

Geraldine Blanchard-Rohner ${ }^{1,2+}{ }^{,}$, Robert J. Ragotte ${ }^{3 \dagger}$, Anne K. Junker ${ }^{1}$, Mehul Sharma ${ }^{1}$, Kate L. Del Bel ${ }^{1}$, Henry Y. Lu', Stephanie Erdle, Alanna Chomyn ${ }^{1}$, Harinder Gill ${ }^{4}$, Lori B. Tucker ${ }^{1}$, Richard A. Schreiber ${ }^{1}$, Jacob Rozmus ${ }^{1}$, Catherine M. Biggs ${ }^{1}$, Kyla J. Hildebrand ${ }^{1}$, John Wu${ }^{1}$, Sylvia Stockler-lpsiroglu ${ }^{1}$ and Stuart E. Turvey ${ }^{1 *}$

\begin{abstract}
Background: KRAS (KRAS proto-oncogene, GTPase; OMIM: 190,070) encodes one of three small guanosine triphosphatase proteins belonging to the RAS family. This group of proteins is responsible for cell proliferation, differentiation and inhibition of apoptosis. Gain-of-function variants in KRAS are commonly found in human cancers. Non-malignant somatic KRAS variants underlie a subset of RAS-associated autoimmune leukoproliferative disorders (RALD). RALD is characterized by splenomegaly, persistent monocytosis, hypergammaglobulinemia and cytopenia, but can also include autoimmune features and lymphadenopathy. In this report, we describe a non-malignant somatic variant in KRAS with prominent clinical features of massive splenomegaly, thrombocytopenia and lymphopenia.
\end{abstract}

Case presentation: A now-11-year-old girl presented in early childhood with easy bruising and bleeding, but had an otherwise unremarkable medical history. After consulting for the first time at 5 years of age, she was discovered to have massive splenomegaly. Clinical follow-up revealed thrombocytopenia, lymphopenia and increased polyclonal immunoglobulins and C-reactive protein. The patient had an unremarkable bone marrow biopsy, flow cytometry showed no indication of expanded double negative T-cells, while malignancy and storage disorders were also excluded. When the patient was 8 years old, whole exome sequencing performed on DNA derived from whole blood revealed a heterozygous gain-of-function variant in KRAS (NM_004985.5:c.37G > T; (p.G13C)). The variant was absent from DNA derived from a buccal swab and was thus determined to be somatic.

Conclusions: This case of idiopathic splenomegaly in childhood due to a somatic variant in KRAS expands our understanding of the clinical spectrum of RAS-associated autoimmune leukoproliferative disorder and emphasizes the value of securing a molecular diagnosis in children with unusual early-onset presentations with a suspected monogenic origin.

Keywords: RAS-associated lymphoproliferative disease, KRAS, Splenomegaly, Case report

\footnotetext{
* Correspondence: sturvey@bcchr.ca

${ }^{\dagger}$ Geraldine Blanchard-Rohner and Robert J. Ragotte contributed equally to this work.

'Department of Pediatrics, British Columbia Children's Hospital, The

University of British Columbia, 950 West 28th Avenue, V5Z 4H4 Vancouver, BC, Canada

Full list of author information is available at the end of the article
}

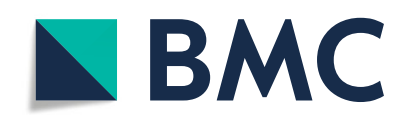

(- The Author(s). 2021 Open Access This article is licensed under a Creative Commons Attribution 4.0 International License, which permits use, sharing, adaptation, distribution and reproduction in any medium or format, as long as you give appropriate credit to the original author(s) and the source, provide a link to the Creative Commons licence, and indicate if changes were made. The images or other third party material in this article are included in the article's Creative Commons licence, unless indicated otherwise in a credit line to the material. If material is not included in the article's Creative Commons licence and your intended use is not permitted by statutory regulation or exceeds the permitted use, you will need to obtain permission directly from the copyright holder. To view a copy of this licence, visit http://creativecommons.org/licenses/by/4.0/. The Creative Commons Public Domain Dedication waiver (http://creativecommons.org/publicdomain/zero/1.0/) applies to the data made available in this article, unless otherwise stated in a credit line to the data. 


\section{Background}

The RAS family consists of three proteins all sharing a highly conserved N-terminus region: Harvey RAS (HRAS), Kirsten RAS (KRAS) and neuroblastoma RAS (NRAS). These guanosine triphosphatases bind GTP causing the activation of mitogen activated protein kinase (MAPK), phosphoinositide-3-kinase (PI3K) and Ras-like (RAL) pathways [1]. Activation leads to cell proliferation, differentiation and inhibition of apoptosis. Downstream signalling is controlled by both RAS-intrinsic GTP hydrolysis, guanine nucleotide exchange factors (GEFs) that catalyse hydrolysis and GTPase-activating proteins (GAPs) [2].

Gain-of-function variants in the three RAS genes have been found in $27 \%$ of human cancers [3]. The disease mechanism underlying these variants is dependent on the specific defect, as some reduce intrinsic GTP hydrolysis, while others result in an insensitivity to GAP-mediated GTP hydrolysis [2]. The majority of these variants are localised to the conserved $\mathrm{N}$-terminus in codons 12, 13 and 61, resulting in greater enhancement of downstream signalling, with variants in codons 12 and 13 most frequently observed for $K R A S[4,5]$. The degree of activation and the underlying biochemical mechanism differs between variants in the three RAS genes, with the KRAS isoform being the most commonly disrupted in human carcinomas [6].

In 2011, somatic gain-of-function KRAS variants were identified as the genetic etiology of a monogenic autoimmune disorder now known as RAS-associated autoimmune leukoproliferative disorder (RALD) [7]. RALD is characterized by splenomegaly, persistent monocytosis, hypergammaglobulinemia and cytopenia, but can also include autoimmune features and lymphadenopathy $[8,9]$. Here we report the discovery of a non-malignant somatic KRAS variant using whole exome sequencing in a minimally symptomatic then-8-year-old girl with unexplained massive splenomegaly.

\section{Case presentation}

The patient is one of twelve siblings of unrelated parents without any contributive familial history. In early childhood, she presented with easy bruising and bleeding from gums upon brushing teeth. Otherwise, she was asymptomatic and her history of infections was unremarkable. The family consulted a haematologist when she was approximately five years-old. A complete blood count revealed thrombocytopenia and lymphopenia (Fig. 1a) with no abnormal cells. Physical examination was notable for a firm and regular spleen with the tip palpable $7 \mathrm{~cm}$ below the costal margin. An abdominal ultrasound confirmed the splenomegaly with a uniform echotexture.
Inborn errors of metabolism associated with splenomegaly (e.g. Gaucher, Niemann Pick A/B and C, Tangier disease) were excluded via demonstration of normal enzyme activities, the absence of biomarkers for the respective conditions, and targeted gene sequencing. A normal bone marrow biopsy ruled out haematological malignancy. Serology showed elevated serum immunoglobulin G, A and M, C-reactive protein, tissue transglutaminase antibodies and smooth muscle antibodies, with normal levels of $\mathrm{C} 3$ and $\mathrm{C} 4$ proteins. She had generated detectable antibodies to vaccine antigens, including diphtheria and tetanus toxoids. Flow cytometry revealed low-normal numbers of $\mathrm{CD}_{4}^{+}, \mathrm{CD}^{+}$and $\mathrm{CD} 19^{+}$cells. $\mathrm{CD}^{+} / \mathrm{TCR} \alpha \beta^{+} \mathrm{CD}^{-} / \mathrm{CD}^{-}{ }^{-}$'double negative' (DN) T-cells were $0.25 \%$, making a diagnosis of autoimmune lymphoproliferative syndrome (ALPS) less likely. Key laboratory findings are documented in Fig. 1a.

Due to her atypical constellation of symptoms without a unifying explanation, singleton whole exome sequencing on DNA derived from blood was performed when the patient was 8 years old. This sequencing revealed a heterozygous missense variant in KRAS - NM_004985.5:c.37G > T(p.G13C), that was present in $20 / 47(=0.42)$ sequence reads. This is a known pathogenic variant reported in Clinvar (Accession ID: VCV000045123.2). Importantly, this specific variant had been previously linked to RASassociated lymphoproliferative disease (RALD) as a non-malignant somatic variation [7]. Follow-up studies showed that the variant was not present in DNA extracted from a buccal swab, confirming the somatic origin of the variant (Fig. 1b). The patient was started on sirolimus $\left(1 \mathrm{mg} / \mathrm{m}^{2} /\right.$ day orally based on body surface area) at age 11 years due to her progressive massive splenomegaly, thrombocytopenia and lymphopenia. Sirolimus was well-tolerated and resulted in objective improvements of the patient's condition, including a reduction in spleen size and improved hematological parameters, and subjective improvements including increased energy and decreased abdominal circumference, reported as clothes fitting more easily. Regular follow-up has been instituted to include physical examinations, laboratory testing and imaging as guided by signs and symptoms.

\section{Discussion and conclusions}

The variant described here (KRAS p.G13C) has been previously identified in patients who presented with an ALPS-like phenotype, but who lacked the defining increase in the $\mathrm{CD}^{+} / \mathrm{TCR} \alpha \beta^{+} \mathrm{CD} 4^{-} / \mathrm{CD}^{-} \mathrm{DN}$ T-cell compartment, elevated biomarkers (i.e. vitamin B12), and the germline or somatic variants in FAS, FASL or CASP10 [8, 12]. We have previously reported the same 


\begin{tabular}{|c|c|}
\hline Initial Laboratory Values & Value (age-specific reference range) \\
\hline Complete Blood Count & $\begin{array}{l}\text { Hemoglobin } 115 \mathrm{~g} / \mathrm{L}(107-147 \mathrm{~g} / \mathrm{L}) \\
\text { Platelets } 72 \times 10^{9} / \mathrm{L}\left(180-440 \times 10^{9} / \mathrm{L}\right) \\
\text { WBC } 4.1 \times 10^{9} / \mathrm{L}\left(5-15 \times 10^{9} / \mathrm{L}\right) \\
\text { Neutrophils } 0.89 \times 10^{9} / \mathrm{L}\left(1.5-8.5 \times 10^{9} / \mathrm{L}\right) \\
\text { Lymphocytes } 1.49 \times 10^{9} / \mathrm{L}\left(2.0-8.0 \times 10^{9} / \mathrm{L}\right) \\
\text { Monocytes } 1.7 \times 10^{9} / \mathrm{L}\left(0.0-0.9 \times 10^{9} / \mathrm{L}\right)\end{array}$ \\
\hline Lymphocyte subsets & 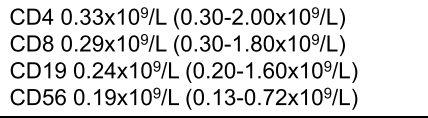 \\
\hline $\begin{array}{l}\mathrm{CD}^{+} / \mathrm{TCR} \alpha \beta^{+} \mathrm{CD} 4-/ \mathrm{CD} 8- \\
\text { 'double negative' T cells }\end{array}$ & $0.25 \%$ (ALPS > 2.0\%) \\
\hline Immunoglobulins & $\begin{array}{l}\lg \text { 23.5g/L }(4.5-13.5 \mathrm{~g} / \mathrm{L}) \\
\operatorname{IgA} 3.24 \mathrm{~g} / \mathrm{L}(0.25-1.9 \mathrm{~g} / \mathrm{L}) \\
\operatorname{IgM} 1.89 \mathrm{~g} / \mathrm{L}(0.31-2.08 \mathrm{~g} / \mathrm{L})\end{array}$ \\
\hline
\end{tabular}

\section{C}

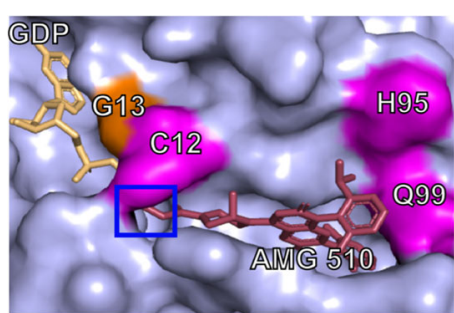

B
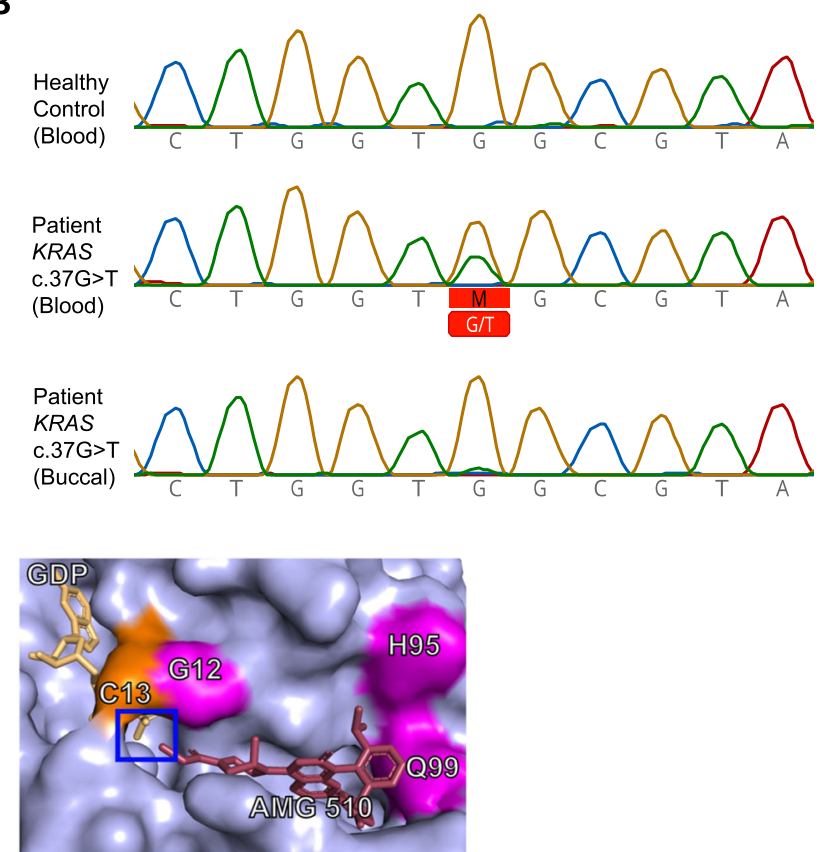

Fig. 1 a Key clinical laboratory findings with age-specific reference intervals. Abnormal values are in bold. b Sanger sequencing of KRAS from DNA extracted from healthy control, patient blood, and a patient buccal swab. This identified a somatic variant in KRAS (NM_004985.5:c.37G > T(p.G13C)) originally discovered by whole exome sequencing on DNA derived from blood. c AMG 510 is a selective KRAS p.G12C inhibitor. AMG510 binding to p.G13C KRAS was modelled using the crystallographic data of covalently-bound AMG-510 and p.G12C KRAS from PDB 6OIM [10]. The p.G13C substitution were introduced using Coot [11]. Cysteine substitution in position 12 instead of 13 of KRAS would likely affect covalent bond formation in the P2 pocket

variant of somatic origin, p.G13C, in a severely affected boy who presented with Rosai-Dorfman syndrome and systemic lupus erythematosus [9].

Massive splenomegaly in children can be indicative of a severe underlying condition including infection, hemoglobinopathies, hematological malignancy, congenital anemia, inborn errors of metabolism (IEM), lysosomal storage diseases, hepatic diseases, autoimmune conditions, and lymphoproliferative disorders such as hemophagocytic lymphohistiocytosis (HLH) or autoimmune lymphoproliferative syndrome (ALPS). RALD is considered to be ALPS-related, but a distinct clinical entity that causes the dysregulation of leukocyte homeostasis $[8,9]$. RALD and juvenile myelomonocytic leukemia (JMML) likely exist on a shared clinical continuum where JMML undergoes additional genetic changes responsible for malignant transformation $[8,13]$. In RALD, immune dysregulation may be caused by resistance to IL2 depletion-dependent apoptosis [12]. T-cells from RALD patients exhibit a resistance to the proapoptotic BIM protein, which mediates activated-cell autonomous death (ACAD), while JMML patients have normal ACAD but defective Fas/Fas ligand-mediated activationinduced cell death (AICD) [12]. Thus, RALD-patients should be followed closely for possible transformation following accumulation of new dysplastic molecular or clonal karyotypic alternations [8].

Hematopoietic stem cell transplantation is not recommended for RALD [8]. Like other ALPS-related syndromes, potential targeted treatments include MAPK inhibitors (e.g. trametinib) and mammalian target of rapamycin (mTOR) inhibitors (e.g. sirolimus and everolimus). Efforts are ongoing to develop inhibitors against specific mutated forms of KRAS for use in cancer therapy, most notably AMG-510, which is a compound that targets the NM_004985.5:c.34G > T(p.G12C) variant in KRAS [10]. This drug effectively blocked downstream signalling, and reduced tumour size in a small trial of patients with lung cancer [10]. If approved, this drug may prove effective at treating RALD patients harbouring the KRAS p.G12C variant. Unfortunately, due to the high specificity of AMG-510 for KRAS p.G12C, it is unlikely to be beneficial for the patient described here, despite the close proximity of the two variants (Fig. 1c). However, like the p.G12C variant, the introduction of a nucleophilic cysteine in the p.G13C variant in our patient may also enable small molecule targeting of this mutant form of KRAS. 
Developing compounds against other common KRAS variants in cancer remains of interest, most notably against p.G12D and p.G13C [5]. Due to the small number of affected individuals with rare diseases such as RALD, patients are often dependent on drugs originally developed for more common diseases. By identifying the specific molecular defect underlying RALD, we can rationally repurpose variant-specific KRAS inhibitors currently in development. This would allow us to switch from treating symptoms to targeting the underlying biochemical dysfunction, a central promise of 'precision medicine'.

In conclusion, this case emphasizes the heterogeneous phenotype of RALD and highlights the value of molecular diagnosis for children with unusual early-onset clinical presentations that could have a monogenic origin.

\section{Abbreviations}

IEM: inborn errors of metabolism; HLH: hemophagocytic lymphohistiocytosis; ALPS: autoimmune lymphoproliferative syndrome; RALD: RAS-associated autoimmune leukoproliferative disorder; JMML: juvenile myelomonocytic leukemia; ACAD: activated-cell autonomous death; AICD: activation-induced cell death; mTOR: mammalian target of rapamycin

\section{Acknowledgements}

We formally acknowledge the patient and her family for entrusting our team with their clinical care.

\section{Authors' contributions}

GBR wrote the first draft of the manuscript. RJR, MS, KLD and HYL helped with the laboratory work and helped in creating the figures. AK, SE, AC, HG, $L T, R S, J R, C M B, K H, J W$ and SS-I all helped in describing the case accurately, and all the investigations specific to their expertise that were performed for the patient. SET guided and supervised all steps of this work. All authors read and approved the final manuscript.

\section{Funding}

This work was supported by funding from Genome British Columbia (SIP007). SET holds the Aubrey J Tingle Professorship in Pediatric Immunology and Canada Research Chair in Pediatric Precision Health Funders had no influence on the content of this manuscript nor the decision to publish

\section{Availability of data and materials}

All relevant data are included in this manuscript and associated figures. However, if more information is required, the datasets analysed for the current study available from the corresponding author on reasonable request.

\section{Ethics approval and consent to participate}

Research study protocols were approved by the University of British Columbia / Children's and Women's Health Centre of British Columbia Research Ethics Board. Parents provided written informed consent to participate and the paediatric patient provided assent.

\section{Consent for publication}

Family have reviewed and approved the final version of this manuscript. Signed written consent is available for review by the Editor of this journal.

\section{Competing interests}

The authors declare that they have no relevant conflicts of interest nor competing interests in relation to this manuscript.

\section{Author details}

${ }^{1}$ Department of Pediatrics, British Columbia Children's Hospital, The University of British Columbia, 950 West 28th Avenue, V5Z 4H4 Vancouver,
BC, Canada. ${ }^{2}$ Children's Hospital of Geneva, University Hospitals Geneva, Geneva, Switzerland. ${ }^{3}$ Jenner Institute, Nuffield Department of Medicine, University of Oxford, Oxford, UK. ${ }^{4}$ Department of Medical Genetics, The University of British Columbia, Vancouver, BC, Canada.

Received: 5 September 2020 Accepted: 14 January 2021

Published online: 21 January 2021

\section{References}

1. Rodriguez-Viciana P, Sabatier C, McCormick F. Signaling specificity by Ras family GTPases is determined by the full spectrum of effectors they regulate. Mol Cell Biol. 2004;24(11):4943-54.

2. Smith MJ, Neel BG, Ikura M. NMR-based functional profiling of RASopathies and oncogenic RAS mutations. Proc Natl Acad Sci U S A. 2013;110(12): 4574-9.

3. Hobbs GA, Der CJ, Rossman KL. RAS isoforms and mutations in cancer at a glance. J Cell Sci. 2016;129(7):1287-92.

4. Prior IA, Lewis PD, Mattos C. A comprehensive survey of Ras mutations in cancer. Cancer Res. 2012:72(10):2457-67.

5. Mullard A. Cracking KRAS. Nat Rev Drug Discov. 2019;18(12):887-91.

6. Munoz-Maldonado C, Zimmer Y, Medova M. A Comparative Analysis of Individual RAS Mutations in Cancer Biology. Front Oncol. 2019:9:1088.

7. Niemela JE, Lu L, Fleisher TA, Davis J, Caminha I, Natter M, Beer LA, Dowdell KC, Pittaluga S, Raffeld M, et al. Somatic KRAS mutations associated with a human nonmalignant syndrome of autoimmunity and abnormal leukocyte homeostasis. Blood. 2011;117(10):2883-6.

8. Calvo KR, Price S, Braylan RC, Oliveira JB, Lenardo M, Fleisher TA, Rao VK. JMML and RALD (Ras-associated autoimmune leukoproliferative disorder): common genetic etiology yet clinically distinct entities. Blood. 2015;125(18): 2753-8.

9. Ragotte RJ, Dhanrajani A, Pleydell-Pearce J, Del Bel KL, Tarailo-Graovac M, van Karnebeek C, Terry J, Senger C, McKinnon ML, Seear M, et al. The importance of considering monogenic causes of autoimmunity: A somatic mutation in KRAS causing pediatric Rosai-Dorfman syndrome and systemic lupus erythematosus. Clin Immunol. 2017;175:143-6.

10. Canon J, Rex K, Saiki AY, Mohr C, Cooke K, Bagal D, Gaida K, Holt T, Knutson CG, Koppada N, et al. The clinical KRAS(G12C) inhibitor AMG 510 drives antitumour immunity. Nature. 2019;575(7781):217-23.

11. Emsley P, Lohkamp B, Scott WG, Cowtan K. Features and development of Coot. Acta Crystallographica Section D Biological Crystallography. 2010;66(4): 486-501.

12. Takagi M, Shinoda K, Piao J, Mitsuiki N, Takagi M, Matsuda K, Muramatsu H, Doisaki S, Nagasawa M, Morio T, et al. Autoimmune lymphoproliferative syndrome-like disease with somatic KRAS mutation. Blood. 2011;117(10): 2887-90.

13. Meynier S, Rieux-Laucat F. FAS and RAS related Apoptosis defects: From autoimmunity to leukemia. Immunol Rev. 2019;287(1):50-61.

\section{Publisher's Note}

Springer Nature remains neutral with regard to jurisdictional claims in published maps and institutional affiliations.

\section{Ready to submit your research? Choose BMC and benefit from:}

- fast, convenient online submission

- thorough peer review by experienced researchers in your field

- rapid publication on acceptance

- support for research data, including large and complex data types

- gold Open Access which fosters wider collaboration and increased citations

- maximum visibility for your research: over $100 \mathrm{M}$ website views per year

At BMC, research is always in progress.

Learn more biomedcentral.com/submission 